Article

\title{
Structural and Thermal Properties of Montmorillonite/Ionic Liquid Composites
}

\author{
Olga Alekseeva ${ }^{1}$, Andrew Noskov ${ }^{1, * \mathbb{C}}$, Elena Grishina ${ }^{1}$, Lyudmila Ramenskaya ${ }^{1}$, \\ Nadezhda Kudryakova ${ }^{1}$, Vladimir Ivanov ${ }^{2,3}{ }^{-1}$ and Alexander Agafonov ${ }^{1}$ \\ 1 G.A. Krestov Institute of Solution Chemistry, Russian Academy of Sciences, Ivanovo 153045, Russia \\ 2 Kurnakov Institute of General and Inorganic Chemistry, Russian Academy of Sciences, \\ Moscow 117901, Russia \\ 3 National Research Tomsk State University, Tomsk 634050, Russia \\ * Correspondence: avn@isc-ras.ru; Tel.: 8-4932-351859
}

Received: 12 July 2019; Accepted: 9 August 2019; Published: 13 August 2019

Abstract: Composites of montmorillonite K10 (MMT K10) and ionic liquid (IL) containing a 1-butyl-3-methyl-imidazolium cation $\left([\mathrm{BMIm}]^{+}\right)$and various anions, such as bis (trifluoromethylsulfonyl) imide $\left(\left[\mathrm{NTf}_{2}\right]^{-}\right)$, trifluoromethanesulfonate $\left([\mathrm{OTf}]^{-}\right)$, and dicyanamide $\left([\mathrm{DCA}]^{-}\right)$have been obtained in this work. A number of methods, such as dynamic light scattering (DLS), scanning electron microscopy (SEM), X-ray diffraction (XRD), thermal gravimetry (TG), differential scanning calorimetry (DSC), Fourier-transform infrared (FTIR) spectroscopy, and nitrogen adsorption-desorption have been used to characterize clay, and to study the structure and thermal behaviour of the composites. It has been found that the MMT K10 powder has a narrow particle size distribution with a peak at $246 \mathrm{~nm}$ and a mesoporous structure $\left(\mathrm{S}_{\mathrm{BET}}=195 \mathrm{~m}^{2} / \mathrm{g}\right)$. According to the FTIR spectra, MMT K10/IL interaction depends on the IL type. It has been identified that confined ionic liquid interacts with both clay and adsorbed water in accordance with the hydrophilicity and size of the anion, in the following order: $[\mathrm{DCA}]^{-}>[\mathrm{OTf}]^{-}>\left[\mathrm{NTf}_{2}\right]^{-}$. Characteristic temperatures of glass transition, crystallization, and melting have been determined for the ionic liquids under study and their MMT K10 composites. It has been revealed that when IL is adsorbed on the surface of clay, the phase transitions in IL change. The greatest changes are observed in the case of BMImNTf 2 . By applying the method of thermogravimetric analysis, it is shown that composite formation is accompanied by a decrease in the IL thermal stability. Apparently, the highly developed surface of montmorillonite K10, obtained by acid treatment, plays a major role in the decrease in the IL's thermal stability. The influence of the IL anion on the thermal and spectral characteristics of an MMT K10/IL composite was studied for the first time.

Keywords: ionic liquid; montmorillonite; porosity; glass transition temperature; thermal stability; FTIR spectra

\section{Introduction}

Increasing attention has recently been paid to the development of functional materials based on clay minerals, found in abundance around the world, due to their use in various industries. The morphology and physico-chemical properties of clay minerals are determined by their high specific surface area and presence of exchangeable cations, hydroxyl groups, and adsorbed water molecules in their structure.

There are a lot of kinds of clays, such as smectite, kaolinite, vermiculite, etc. [1]. Among them, montmorillonite (MMT) is a natural and cost-effective clay that belongs to the structural family known as the 2:1 phyllosilicates, consisting of a tetrahedral sheet sandwiched between two parallel octahedral 
sheets [2-4]. Stacking of these layers generates van der Waals gaps or "galleries". The galleries are occupied by inorganic cations, such as $\mathrm{Na}^{+}, \mathrm{Ca}^{2+}$, and $\mathrm{Mg}^{2+}$. Due to its high surface area, cation intercalation, and excellent thermal stability, MMT is a material of great interest to researchers working in areas related to adsorption and catalysis, as well as the development of sensors, filtration membranes, and membranes for Li-ion batteries [5].

Interlayer cations in MMT are capable of ion exchange, and can be replaced by other inorganic or organic ions, metal nanoparticles, metal oxides, or metal-organic compounds [6-8]. This allows for the creation of composite nanomaterials with new properties, such as photocatalytic, catalytic, adsorption, mechanical, and thermal stability.

Recently, there has been interest in nanocomposites of montmorillonite with ionic liquids $[9,10]$. This composite material retains the chemical inertness, low vapor pressure, and high electrical conductivity inherent in ionic liquids, and significantly reduces its fluidity. In addition, an expensive component can be replaced by a cheaper one, while maintaining the unique properties of ionic liquids. In some cases, interlayer cations in montmorillonite can be replaced by inorganic or organic cations from ionic liquids [11].

The modification of clay minerals opens up the opportunity for obtaining new materials with special properties, as well as potential technical and environmental applications. The use of ionic liquids in MMT modification has drawn attention because the ionic exchange with these compounds allows an easy organic modification in clay minerals.

Ionic liquids are a new class of solvents (green solvents): salts that are liquid at room temperature, consisting of organic cations and organic or inorganic anions. Due to their unique characteristics, such as low volatility, non-flammability, high thermal stability (up to $400{ }^{\circ} \mathrm{C}$ ), and high ionic conductivity, ILs can be used in many important applications, such as catalysis and extraction, as well as electrolytes in electrical devices (e.g., batteries, capacitors, fuel cells, and solar cells) and in different electrochemical processes (e.g., the dissolution of metals, coating, and polishing) [12-15]. For the successful resolution of electrochemical issues, theoretical studies of ILs are required. In this regard, it is necessary to mention the work of Fedorov and Kornyshev [16,17], in which the authors performed molecular dynamics simulations and analyzed the structure of the double layer for some ionic liquid models.

Ionic liquids can be produced with a variety of cations and anions. Most of the ILs used for MMT modification have cations based on imidazolium, pyridinium, and pyrrolidinium ions [18,19]. Certainly, the presence of IL organic cations in the MMT structure increases the hydrophobicity of the mineral clay, and makes it suitable for absorbing organic substances as pollutants [11,20].

As a result of interaction with clays, ionic liquids change fluidity, the temperature interval of the liquid state, and thermal stability, while maintaining electrical conductivity. The physical and chemical properties of such composites depend on the interaction of the ionic liquid with the porous space of the clay. In this case, due to the confinement effect, the properties of both the inorganic component and the ionic liquid change, which leads to a change in the characteristics of the resulting material. The interactions in such systems are difficult to predict a priori, since the properties of the obtaining materials are influenced by many factors related both to the features of the clay nanostructure and the properties of ionic liquids. The mechanisms of interactions between ILs, clays, and the interlayer configurations of ILs are still debated [21].

In present work, the montmorillonite K10 was modified by ionic liquids, which have a 1-butyl-3-methylimidazolium cation with various anions: bis (trifluoromethylsulfonyl) imide, trifluoromethanesulfonate, or dicyanamide.

MMT K10 is an acid-activated clay, in which the edges of crystals open during acid treatment and the octahedral cations ( $\mathrm{Al}$ or $\mathrm{Mg}$ ) are leached from the MMT structure. This results to the gradual destruction of the octahedral layers and an increase in surface area to $220-270 \mathrm{~m}^{2} / \mathrm{g}$, whereas for natural clay this value is near $20 \mathrm{~m}^{2} / \mathrm{g}$ [22].

The structure of the cation and anions in the IL under study is shown in Figure 1. 


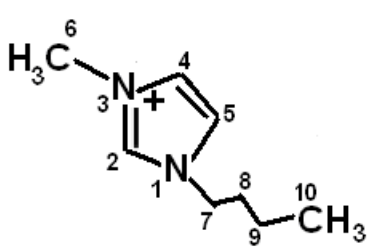

(a)

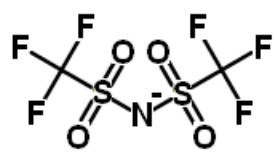

(b)

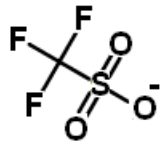

(c)

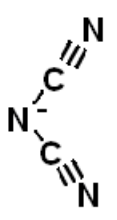

(d)

Figure 1. Structural formula of (a) a 1-butyl-3-methylimidazolium cation [BMIm] ${ }^{+}$, as well as (b) bis(trifluoromethylsulfonyl)imide $\left[\mathrm{NTf}_{2}\right]^{-}$, (c) trifluoromethanesulfonate $[\mathrm{OTf}]^{-}$, and (d) dicyanamide [DCA $]^{-}$anions.

These ionic liquids were chosen because of their high long-time thermostubility, conductivity, and low viscosity, as well as their different hydrophobicity, structure, and size of anions [23-25]. Along with strong electrostatic interactions, these compounds can form $\mathrm{H}$-bonds through various electron-donating atoms, such as $\mathrm{N}, \mathrm{O}$, and F, in the anion and electron-accepting $\mathrm{H}$ atoms in the cation [26]. Moreover, these salts are of interest for use in electrochemical technologies and electrochemical devices [27,28], due to their low corrosivity [29]. The thickened ionic liquids are promising for use in solid-state devices [30]

The main purpose of the present research was to identify changes in the properties of composites as a result of MMT K10 modification with the listed IL. For this, the structure and morphology of the obtained samples were characterized using different techniques, such as X-ray diffraction (XRD), FTIR, and scanning electron microscopy (SEM). The effect of clay on the thermodynamic properties of ionic liquids was also studied.

\section{Materials and Methods}

\subsection{Materials}

The montmorillonite K10 (Acros organics, Catalog No. AC456071000, Pittsburgh, PA, USA) was used without additional processing. MMT K10 is an acid-activated and thermally treated montmorillonite. During the acidic treatment, the crystal structure of the montmorillonite becomes partially destroyed, which leads to the formation of a highly porous substance with a larger surface area and nanopores. As a result of the thermal treatment, MMT K10 almost loses its ability to swell [30,31].

The ionic liquids of 1-butyl-3-methyl-imidazolium bis (trifluoromethylsulfonyl) imide (Sigma-Aldrich, CAS Number: 174899-83-3, for synthesis, Saint Louis, MO, USA), 1-butyl-3-methylimidazolium trifluoromethanesulfonate (Sigma-Aldrich, CAS Number: 74899-66-2, for synthesis, Saint Louis, MO, USA), and 1-butyl-3-methylimidazolium dicyanamide (Sigma-Aldrich, CAS Number: 448245-52-1, purity $\geq 97 \%$, Hong Kong, China) were used without further purification.

The MMT K10/IL composites were obtained by direct mixing of the components with a vibration shaker IKA VORTEX 4 Basic (IKA-Werke GmbH \& Co, Breisgau, Germany). The mixture was kept in a vacuum drying oven LT-VO/20 (Labtex, Moscow, Russia) at a temperature of $80{ }^{\circ} \mathrm{C}$ for $8 \mathrm{~h}$. The obtained mechanical dispersions of the clay mineral particles in the IL were additionally treated in hermetically sealed capsules in an ultrasonic bath CT-431D2 (CTbrand Wahluen Electronic TOOL Co. Ltd., Hong Kong, China) for $8 \mathrm{~h}$. The obtained mixtures had the molar ratio of the IL:MMT K10 components as 2:1, which corresponded to $53.5 \mathrm{wt} \%$ of BMImDCA, $61.6 \mathrm{wt} \%$ of BMImOTf, and $69.9 \mathrm{wt} \%$ of $\mathrm{BMImNTf}_{2}$ in the obtained ionogels. 


\subsection{Methods and Apparatus}

\subsubsection{Dynamic Light scattering (DLS)}

Dynamic light scattering (DLS) (Malvern Zetasizer Nano ZS, Malvern, UK) was used to monitor the particle size (radius) in the $0.2-5000 \mathrm{~nm}$ range. Before testing, a suspension of clay in distilled water was prepared, sonicated, and kept for $24 \mathrm{~h}$.

\subsubsection{Scanning Electron Microscopy (SEM)}

The surface morphology and composition of the MMTK10 powder and MMT K10 samples modified by an ionic liquid were investigated using a Tescan Vega 3 SBH (TESCAN, Brno, the Czech Republic) scanning electron microscope equipped with an energy-dispersive X-ray spectroscopy (EDX) detector. For testing, the MMTK10 and MMT K10/IL samples were placed on carbon tape. Then a layer of carbon $1 \mathrm{~nm}$ thick was applied to the samples. The MMT K10 particle sizes were determined using VEGA3 Control software.

\subsubsection{Nitrogen Vapor Adsorption-Desorption}

The MMTK10 porosity quantitative parameters were determined by the method of low-temperature $(77 \mathrm{~K})$ nitrogen vapor adsorption-desorption with a Quanta Chrome Nova 1200 (Quantachrome Corporation, Boynton Beach, FL, USA) surface area analyzer. Before the adsorption measurements, the powder had been degassed at $90^{\circ} \mathrm{C}$ for $7 \mathrm{~h}$. The isotherms were analysed using the Brunauer-Emmett-Teller (BET) and Barrett-Joyner-Halenda (BJH) models.

\subsubsection{X-Ray Diffraction (XRD)}

The crystal structure of the MMTK10 powder and MMT K10 samples modified by an ionic liquid was investigated by X-ray diffraction in the angle range of $2 \theta=5^{\circ}-50^{\circ}$ using a DRON-UM1 (Russia) diffractometer $\left(\mathrm{CuK}_{\alpha}\right.$ radiation, $\left.\lambda=0.154 \mathrm{~nm}\right)$, operating at a voltage of $40 \mathrm{kV}$ and a current of $40 \mathrm{~mA}$.

\subsubsection{Fourier-Transform Infrared (FTIR) Spectroscopy}

A VERTEX 80v infrared-Fourier spectrometer (Bruker, Karlsruhe, Germany) was used for the spectrophotometric measurements. The FTIR reflection spectra were recorded in the region from 400 to $4000 \mathrm{~cm}^{-1}$ at room temperature, and the resolution was $2 \mathrm{~cm}^{-1}$. The measurements were carried out in a thin layer of IL deposited on a diamond crystal, by casting at ambient temperature.

\subsubsection{Thermogravimetric Measurements}

Thermogravimetric analysis was performed using a TG 209 F1 thermal analyzer (NETZSCH, Selb, Germany). The samples of about $10 \mathrm{mg}$ in a platinum crucible were heated in an argon flow $\left(30 \mathrm{~mL} / \mathrm{min}\right.$ ) at a rate of $10^{\circ} \mathrm{C} / \mathrm{min}$ to a temperature of $600-800^{\circ} \mathrm{C}$, and the weight loss was measured. The accuracy of the sample mass measurement was $1 \times 10^{-6} \mathrm{~g}$, and the accuracy of the temperature measurement was $0.1^{\circ} \mathrm{C}$. Three TG scans were performed for each sample.

\subsubsection{Differential Scanning Calorimetry (DSC)}

A DSC 204 F1 Phoenix calorimeter (NETZSCH, Selb, Germany) was used to determine the thermodynamic parameters, such as the melting point $\left(\mathrm{T}_{\mathrm{m}}\right)$, crystallization $\left(\mathrm{T}_{\mathrm{c}}\right)$, glass transition temperature $\left(\mathrm{T}_{\mathrm{g}}\right)$, and the heat capacity change $\left(\Delta C_{\mathrm{p}}\right)$ of phase transition. The sample of approximately $10 \mathrm{mg}$ in a hermetically sealed platinum pan was heated to $80^{\circ} \mathrm{C}$, cooled with liquid nitrogen to $-110^{\circ} \mathrm{C}$, and then heated to $150^{\circ} \mathrm{C}$. The rate of both cooling and heating was $10^{\circ} \mathrm{C} / \mathrm{min}$. The measurements were carried out in an argon atmosphere. The accuracy of the temperature measuring was $\pm 0.1^{\circ} \mathrm{C}$. 


\section{Results and Discussion}

\subsection{Characterization of Montmorillonite K10 Powder}

The results of the MMT K10 particle size distribution, obtained using DLS, are presented in the form of a histogram in Figure 2a. As shown, the sizes of most of the particles lie within the range from 200 to $300 \mathrm{~nm}$. The particle size distribution is monomodal, with a peak at $246 \mathrm{~nm}$.
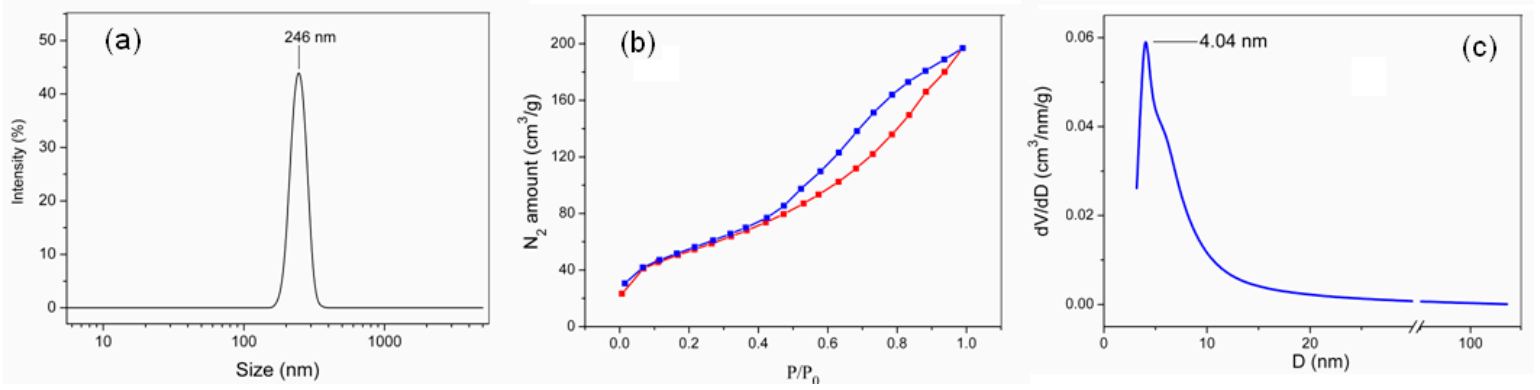

Figure 2. Characterization of montmorillonite (MMT) K10 powder: (a) Size distribution by intensity (dynamic light scattering (DLS)) particles; (b) isotherms of low-temperature nitrogen adsorption-desorption on particles; (c) Barrett-Joyner-Halenda (BJH) pore size distribution for MMT K10.

In order to determine the structural and adsorption parameters of the MMT K10 powder, the nitrogen adsorption/desorption isotherm was recorded. Figure $2 b$ shows that the nitrogen adsorption/desorption isotherm belongs to type IV, according to the IUPAC classification [32]. The following parameters were determined by this technique: the specific surface area of the MMT $\mathrm{K} 10$ according to $\mathrm{BET}$, which is $195 \mathrm{~m}^{2} / \mathrm{g}$; the total pore volume, which is $0.305 \mathrm{~cm}^{3} / \mathrm{g}$; and the average pore size, which is $6.25 \mathrm{~nm}$.

Figure 2c shows the pore size distribution curve obtained using the BJH model. We can see that $80 \%$ of the total pore volume is pores with a diameter smaller than $25 \mathrm{~nm}$. This provides evidence for the framework mesoporosity of the clay. It can be seen that the pore size distribution is monomodal, with a peak at $4.04 \mathrm{~nm}$.

The scanning electron microscopic technique was used to explore the surface morphology of both MMT K10 and MMT K10/IL composite. The clay samples have the shape of polydisperse particles 150-300 $\mathrm{nm}$ in size, in the form of agglomerates (Figure 3a). These results agree with the data obtained by the DLS method.

An EDX analysis was also performed (Figure 3b). The main elements in pure MMT K10 are oxygen (about $62.85 \%$ ) and silicon (about $27.66 \%$ ). At the same time, the clay spectrum contains $\mathrm{Al}$ (5.81\%), K (0.63\%), and $\mathrm{Mg}(0.80 \%)$ elements.

\subsection{Structure and Properties of the Montmorillonite K10/IL Composite Materials}

\subsubsection{Surface Morphology and Composition}

The surface morphology of the MMT K10/IL composites was researched using SEM and is presented in Figure 4a,c,e. It can be seen that the MMT K10/IL composite shows a massive, thinly layered structure, with some interlayer spaces and large flakes. This may be attributed to the chemical modification by large alkyl moieties in the clay galleries. Thus, the MMT K10/IL composite is an ionic liquid filled with aggregated montmorillonite particles, which play the role of thickeners, and the ionic liquid completely surrounds the clay particles. 

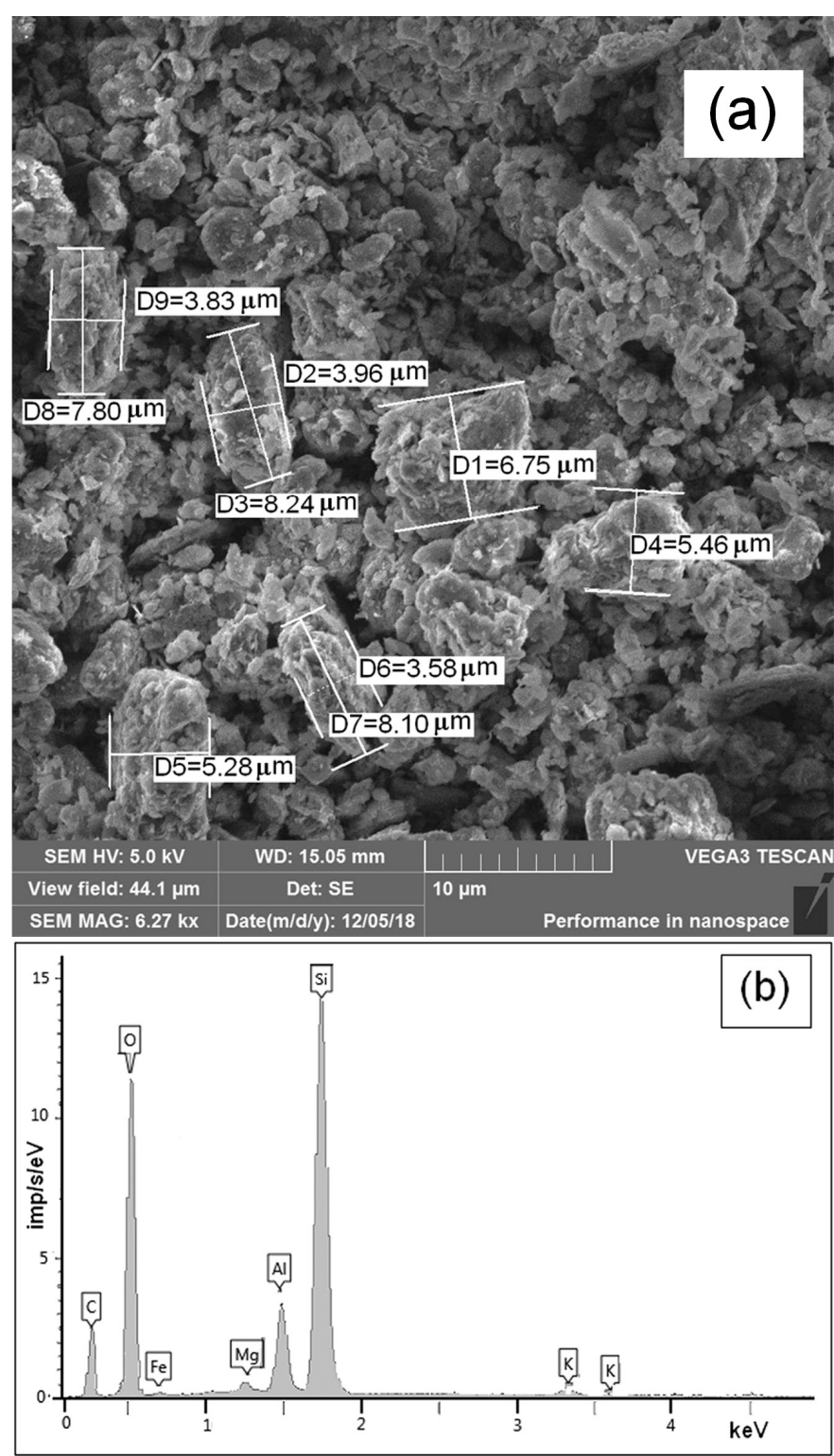

Figure 3. Scanning electron microscope (SEM) image (a) and energy-dispersive X-ray spectroscopy (EDX) analysis (b) of the MMT K10.

Figure $4 b, d, f$ shows the results of the EDX analysis for the MMT K10/IL under study. In addition to oxygen and silicon as the main elements of MMT K10, these composites contain sulfur, fluorine, and nitrogen, which are component parts of ionic liquids. 

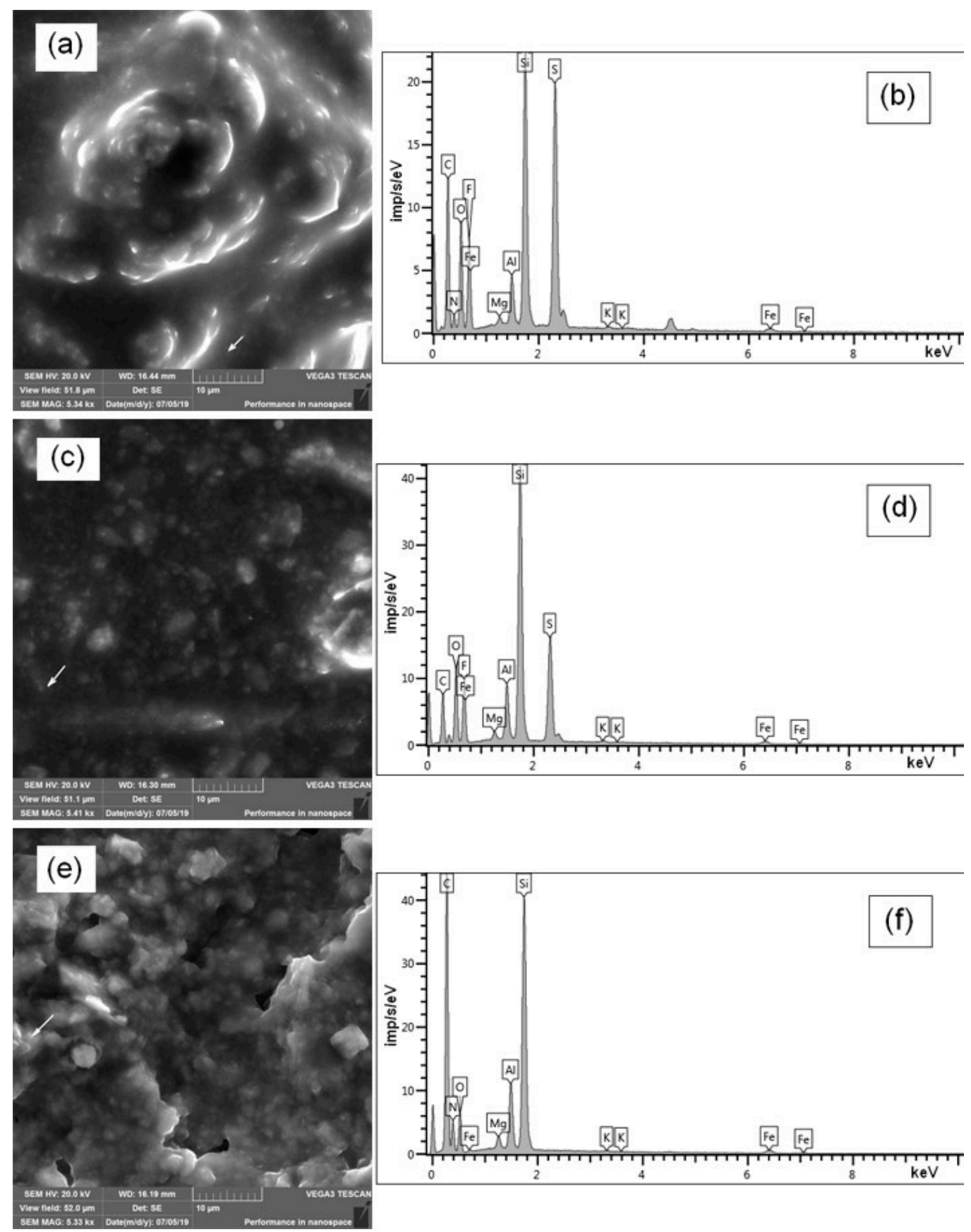

Figure 4. SEM-images (left) and EDX analysis (right) of the samples of MMT K10/BMImOTf (a,b), MMT K10/BMImDCA (c,d), and MMT K10/BMImNTf 2 (e,f).

\subsubsection{Crystal Structure of the Montmorillonite K10/IL Composites}

Figure 5a-d shows the diffraction patterns of X-ray scattering for the MMT K10 and MMT K10/IL composites. These patterns contain reflections corresponding to MMT((001), (002), (110), (220)) and quartz ((101), (112)). The enumerated peaks are characteristic of both the original clay and the materials containing an IL. In addition, the introduction of ILs leads to minimal changes in the crystal structure of the clay. This is confirmed by the data in Table 1. Regardless of the IL's nature, during the composite formation, the reflexes are shifted by no more than 0.3 degrees, and the interlayer distance $(d)$ in the MMT K10, calculated by Bragg's law, changes by no more than $0.015 \mathrm{~nm}$. 


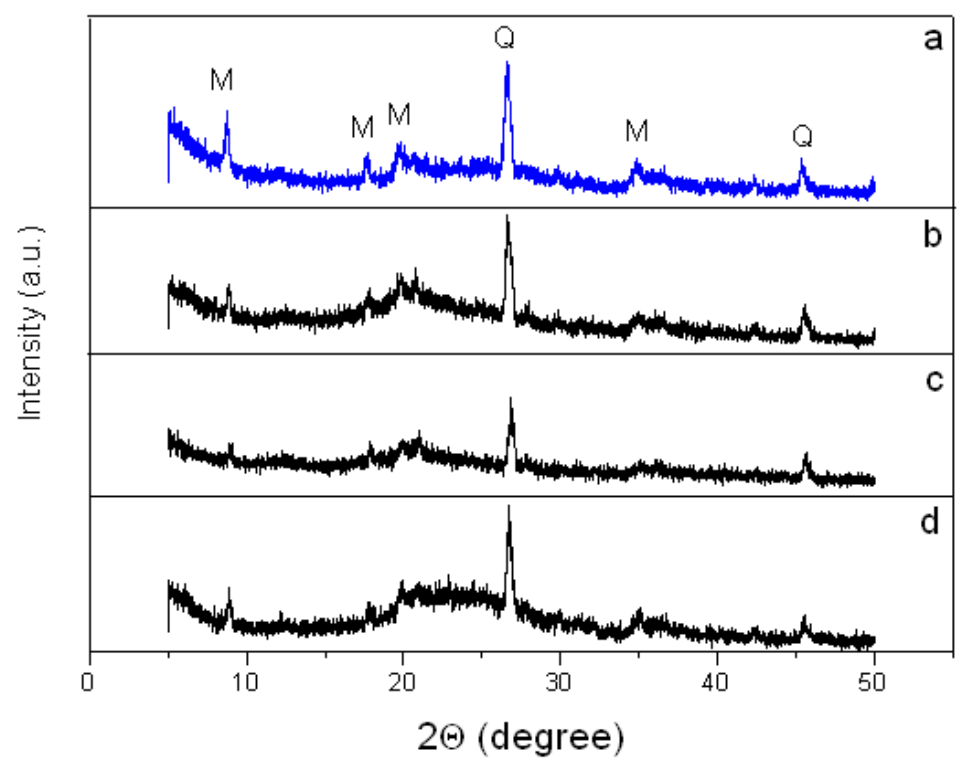

Figure 5. X-ray diffraction (XRD) patterns for MMT K10 (a), MMT K10/BMImOTf (b), MMT K10/BMImNTf 2 (c), and MMT K10/BMImDCA (d).

Table 1. Results of X-ray spectral analysis for MMT K10 and MMT K10/IL composites.

\begin{tabular}{ccccccccc}
\hline \multirow{2}{*}{$\begin{array}{c}\text { Reflection } \\
\text { Index }\end{array}$} & \multicolumn{2}{c}{ MMT K10 } & \multicolumn{2}{c}{ MMT/BMImOTf } & \multicolumn{2}{c}{ MMT/BMImNTf } & \multicolumn{2}{c}{ MMT/BMImDCA } \\
\cline { 2 - 8 } & $\mathbf{2 \theta}, \mathbf{d e g}$ & $\boldsymbol{d}, \mathbf{n m}$ & $\mathbf{2 0 , \mathbf { d e g }}$ & $\boldsymbol{d}, \mathbf{n m}$ & $\mathbf{2 \theta}, \mathbf{d e g}$ & $\boldsymbol{d}, \mathbf{n m}$ & $\mathbf{2 \theta}, \mathbf{d e g}$ & $\boldsymbol{d}, \mathbf{n m}$ \\
\hline$(001)$ & 8.74 & 1.011 & 8.88 & 0.995 & 8.91 & 0.992 & 8.87 & 0.996 \\
$(002)$ & 17.67 & 0.502 & 17.84 & 0.497 & 17.87 & 0.496 & 17.76 & 0.499 \\
$(110)$ & 19.65 & 0.451 & 19.64 & 0.452 & 19.85 & 0.447 & 19.95 & 0.445 \\
$(101)$ & 26.54 & 0.336 & 26.60 & 0.335 & 26.84 & 0.332 & 26.76 & 0.333 \\
$(220)$ & 34.85 & 0.257 & 34.94 & 0.257 & 35.0 & 0.256 & 34.96 & 0.256 \\
$(112)$ & 45.38 & 0.200 & 45.55 & 0.199 & 45.68 & 0.198 & 45.53 & 0.199 \\
\hline
\end{tabular}

As Table 1 shows, in the studied materials, the value $d_{001}$ is equal to about $1 \mathrm{~nm}$. This value is a sum of the thickness of the silicate plate $(0.96 \mathrm{~nm})$ and the gallery thickness [33]. Taking into account that the diameter of the [BMIm] $]^{+}$cation is $0.66 \mathrm{~nm}$ [34], it can be concluded that the IL is mostly adsorbed on the clay surface. Evidently, the ionic liquid promotes partial dehydration of the interlayer space. It should be also said that this supposition agrees with the TG analysis and FTIR spectroscopy results described below.

Note that position of the (001) reflection for MMT K10 is discussed in publications. Also, different researchers come to different conclusions. For instance, the authors of [35] did not observe this peak in montmorillonite K10. They explained that this may be due to the damage to the clay layers caused during acid treatment, but the reflection observed at $9^{\circ}$ creating doubt about the (001) peak is due to the illite impurity present in the clay. Other researchers observed in MMT K10 a wide (001) reflection at lower angles (about 5.8 $8^{\circ}$ [36]. According to them, this peak corresponds to remaining montmorillonite, reflecting a quite disordered stacking in the layers. Therefore, it is difficult to draw final conclusions about changes in the crystalline structure of clay with the introduction of IL.

In addition, we calculated the crystallite size using the XRD data and Scherrer's formula. We found the montmorillonite K10 plate width was $34.6 \mathrm{~nm}$. This size is smaller than the particle size of montmorillonite, according to SEM (Figure 3a). Apparently, montmorillonite particles contain many crystallites. Therefore, in our opinion, it is not entirely correct to compare the particle sizes obtained using XRD and SEM. 


\subsubsection{Phase Transitions in the Montmorillonite K10/IL Composites}

Figure 6a-c show thermograms of the second heating cycles for the studied ILs and MMT $\mathrm{K} 10 / \mathrm{IL}$ composites recorded by the DSC method in the temperature range from -130 to $+280{ }^{\circ} \mathrm{C}$. In these thermograms, the inflection point of the curve corresponds to the glass transition temperature, the exothermic peak $\left(T_{c}\right)$ corresponds to crystallization, and endothermic peak $\left(T_{m}\right)$ corresponds to melting.
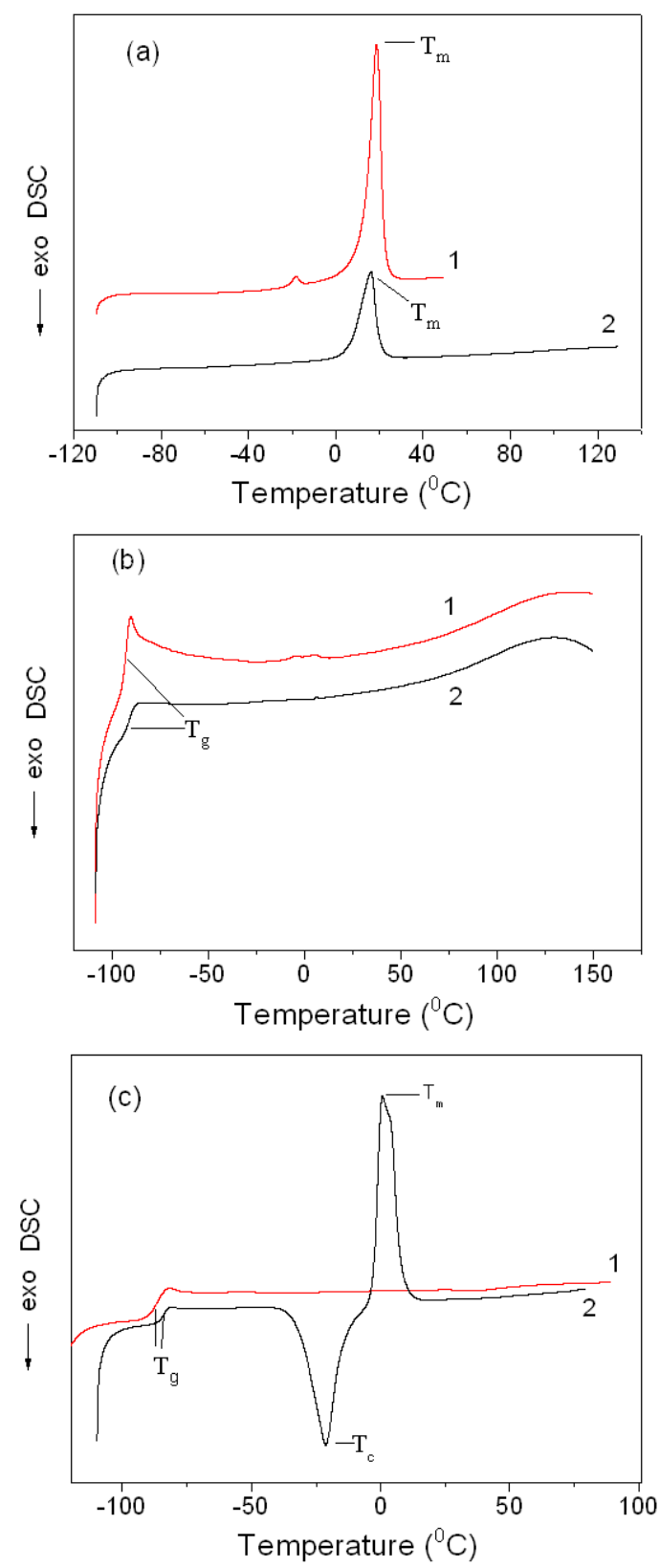

Figure 6. Differential scanning calorimetry (DSC) curves of the second heating cycle (a) 1: BMImOTf, 2: MMT K10/BMImOTf; (b) 1: BMImNTf 2, 2: MMT K10/BMImNTf 2 ; (c) 1: BMImDCA, 2: MMT K10/BMImDCA.

As Figure 6a shows, when the BMImOTf and composites containing this ionic liquid are heated, the thermograms have an endothermic peak corresponding to melting. Other phase transitions are not observed. The characteristic temperatures of the thermal behaviour of the ionic liquid and its composite with the clay are given in Table 2. 
Table 2. Characteristic temperatures of thermal behaviour of the samples under study, determined by DSC.

\begin{tabular}{cccc}
\hline Sample & $T_{g},{ }^{\circ} \mathrm{C}$ & $T_{c},{ }^{\circ} \mathrm{C}$ & $T_{m},{ }^{\circ} \mathbf{C}$ \\
\hline BMImOTf & & & 18.7 \\
MMT K10/BMImOTf & & & 16.2 \\
BMIm DCA & -92.7 & & \\
MMT K10/BMImDCA & -91.6 & & \\
BMImNTf $_{2}$ & $-86.3--86.8^{\mathrm{a}}$ & $-48.6^{\mathrm{b}}--46.3^{\mathrm{a}, \mathrm{b}}$ & $-6.5^{\mathrm{b}}--6.5^{\mathrm{a}, \mathrm{b}}$ \\
MMT K10/BMImNTf $_{2}$ & -83.5 & -19.3 & 0.7 \\
\hline
\end{tabular}

a. Reported in [37]; b. The onset temperature of exothermic $\left(T_{c}\right)$ and endothermic $\left(T_{m}\right)$ peaks detected in the first heating cycle.

The thermal behaviour of the BMImDCA and MMTK10/BMImDCA composites are different. As Figure $6 \mathrm{~b}$ shows, there is a phase transition caused by glass transition processes in the low-temperature regions $\left(-90--95^{\circ} \mathrm{C}\right)$ of such systems. It should be said that the specific heat change $\left(\Delta C_{\mathrm{p}}\right)$ in the MMT/BMImDCA composite is much smaller than in the pure IL: $\approx 0.2 \mathrm{~J} /(\mathrm{g} \cdot \mathrm{K})$ for the composite and $\approx 0.6 \mathrm{~J} /(\mathrm{g} \cdot \mathrm{K})$ for BMImDCA.

Figure $6 \mathrm{c}$ shows DSC curves for BMImTf $\mathrm{B}_{2} \mathrm{~N}$ and the MMT K10/BMImNTf 2 composite. As it indicates, in this case, the thermogram has an inflection point corresponding to $T_{g}$. As Table 2 shows, that clay introduction into the IL increases the glass transition temperature of $\mathrm{BMImNTf}_{2}$ by $3{ }^{\circ} \mathrm{C}$. This inflection is observed both in the first and the second heating cycles. In addition, heating of the MMT K10/BMImNTf 2 composite leads to the appearance of a broad exothermic peak of crystallization, and then to an endothermic peak of melting. However, in case of the IL, there are no crystallization

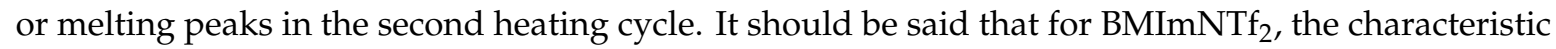
temperatures found in the first heating are close to the data reported previously [37].

Thus, when the IL is adsorbed on the clay surface, the phase transitions in the IL change. The greatest changes are observed in the case of $\mathrm{BMImNTf}_{2}$, which is consistent with the data of the FTIR spectroscopy described below.

\subsubsection{Thermal Degradation of the Montmorillonite K10/IL Composites}

Figure 7a-c show TG curves recorded for the studied ILs and MMT K10/IL composites. It can be seen that the thermal degradation of the studied materials proceeds in several stages. The onset and end temperatures $\left(T_{1}\right.$ and $\left.T_{2}\right)$ and the weight loss $\left(\Delta \mathrm{m}_{\mathrm{i}}\right)$ of each of the stage, as well as temperature corresponding to the maximum thermal decomposition rate $\left(T_{d}\right)$ were determined and are presented in Table 3.

At the first stage, the mass reduction in the samples $\left(\Delta \mathrm{m}_{1}\right)$ did not exceed $5 \%$, and evidently, it was caused by the water removal. It was also accompanied by a considerable widening of the temperature range (by $40-50{ }^{\circ} \mathrm{C}$ ) of the first stage for the composites, in comparison with the individual ILs. This effect may be due to the interaction of IL with clay. Comparing the $\Delta \mathrm{m}_{1}$ values for the composites studied (Table 3), we can conclude that this value is maximum for MMT K10/BMImDCA. Therefore, the origin of the anion in the IL affects the intensity of water removal from the composite. 

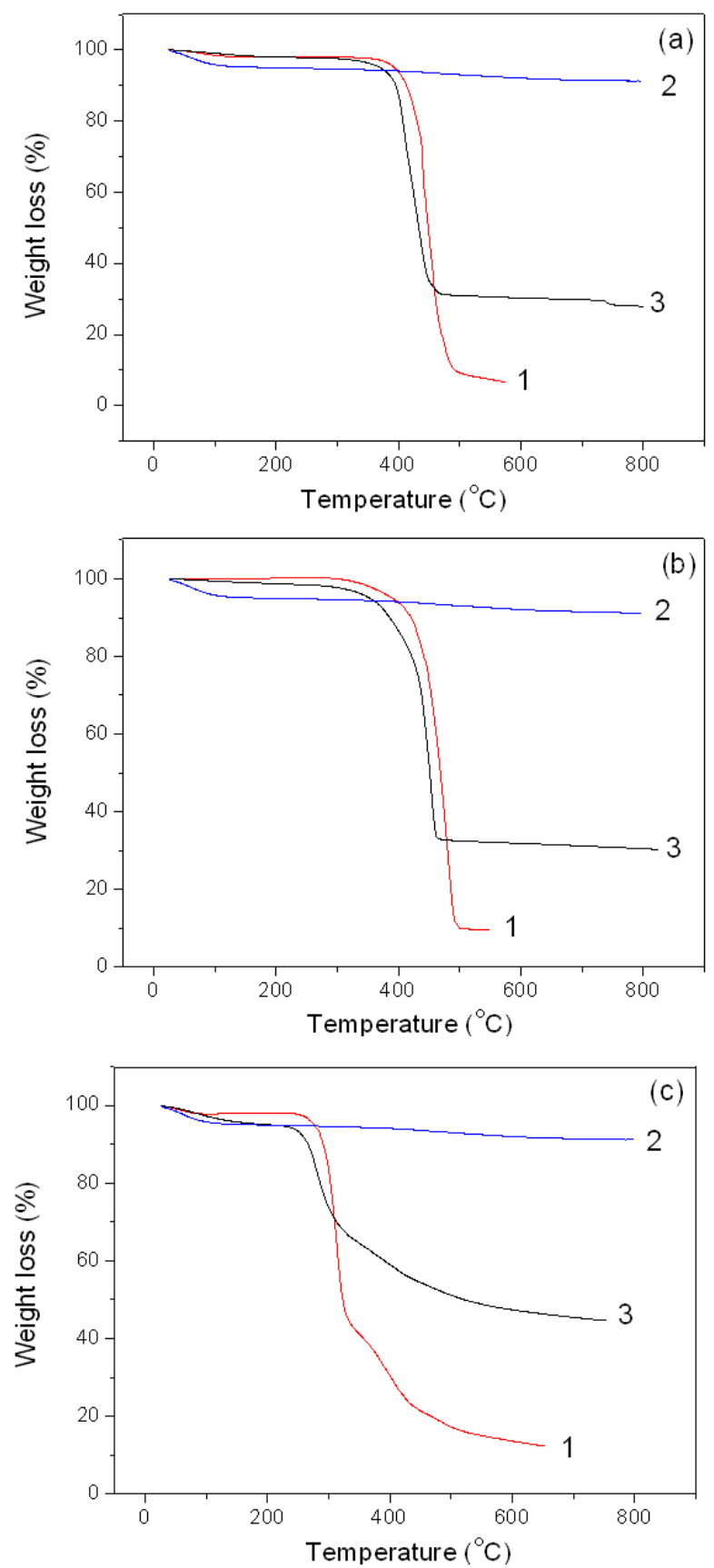

Figure 7. TG curves: (a) 1: BMImOTf, 2: MMT K10, and 3: MMT K10/BMImOTf; (b) 1: BMImNTf 2 , 2: MMT K10, and 3: MMT K10/BMImNTf ${ }_{2}$ (c) 1: BMImDCA, 2: MMT K10, and 3: MMT K10/BMImDCA.

The second stage is characterized by a sharp change in the mass of the samples, and is associated with the IL thermolysis itself. At this stage, the $\Delta \mathrm{m}_{2}$ values exceed $90 \%$ for the individual BMImOTf and BMImNTf ${ }_{2}$, as well as about $68 \%$ for their composites. It should be noted that for the samples based on BMImOTf and BMImNTf 2 , further heating (to $800{ }^{\circ} \mathrm{C}$ ) does not result in thermal decomposition of the samples, which is associated with the clay stability in the composites.

Figure 7c shows that the thermal behaviour of materials based on DCA is different. For these materials, the decomposition thermograms have a third stage, at which there occurs a slow mass loss. It is associated with the degradation of the $[\mathrm{BMIm}]^{+}$cation, which is more stable than the [DCA $]^{-}$ anion $[38,39]$. 
Table 3. Characteristic temperatures $(T)$ and mass loss $\left(\Delta \mathrm{m}_{\mathrm{i}}\right)$ of the thermal decomposition of the samples under study.

\begin{tabular}{|c|c|c|c|c|c|c|}
\hline Parameter & BMImOTf & $\begin{array}{c}\text { MMT } \\
\text { K10/BMImOTf }\end{array}$ & BMImNTf & $\begin{array}{c}\text { MMT } \\
\text { K10/BMImNTf }\end{array}$ & BMImDCA & $\begin{array}{c}\text { MMT } \\
\text { K10/BMImDCA }\end{array}$ \\
\hline \multicolumn{7}{|c|}{ First stage } \\
\hline$T_{1},{ }^{\circ} \mathrm{C}$ & 54.3 & 61.9 & - & 53.3 & 40.1 & 52.2 \\
\hline $\mathrm{T}_{2},{ }^{\circ} \mathrm{C}$ & 110.1 & 164.2 & - & 119.0 & 80.6 & 130.2 \\
\hline$\Delta \mathrm{m}_{1}, \%$ & 1.9 & 2.1 & - & 1.3 & 1,9 & 4.9 \\
\hline \multicolumn{7}{|c|}{ Second stage } \\
\hline$T_{1},{ }^{\circ} \mathrm{C}$ & 427.7 & 392.8 & 441.1 & 425.2 & 293.7 & 260.7 \\
\hline$T_{d},{ }^{\circ} \mathrm{C}$ & 440.9 & 408.9 & 481.5 & 453.8 & 313.5 & 280.4 \\
\hline$T_{2},{ }^{\circ} \mathrm{C}$ & 462.8 & 449.5 & 500.1 & 460.4 & 324.1 & 303.7 \\
\hline$\Delta \mathrm{m}_{2}, \%$ & 91.6 & 67.7 & 90.4 & 68.6 & 57.4 & 30.9 \\
\hline \multicolumn{7}{|c|}{ Third stage } \\
\hline$T_{1},{ }^{\circ} \mathrm{C}$ & - & - & - & - & 372.1 & 374.9 \\
\hline$T_{d},{ }^{\circ} \mathrm{C}$ & - & - & - & - & 393.0 & 385.8 \\
\hline$T_{2},{ }^{\circ} \mathrm{C}$ & - & - & - & - & 428.4 & 482.0 \\
\hline$\Delta \mathrm{m}_{3}, \%$ & - & - & - & - & 28.4 & 20.1 \\
\hline
\end{tabular}

It is worth mentioning that at the transition from the IL to the MMT K10/IL composite, values of $T_{1}, T_{d}$, and $T_{2}$ decrease considerably, which is reflected in the shift of the TG curves to the region of lower temperatures. This means that the introduction of the IL to the composite with MMT K10 reduces its thermal stability. This effect is observed regardless of the nature of the studied ionic liquid, and is evidently associated with the weakening of the ionic liquid cation and anion bonds, as well as the formation of intermolecular bonds with the active groups of the alumosilicate, which is confirmed by the FTIR data discussed below.

Therefore, when interacting with clay, the thermal behaviour of the ionic liquid changes significantly. This may be used to regulate the properties of materials based on IL.

\subsubsection{FTIR Spectra of the Montmorillonite K10/IL Composites}

The FTIR reflection spectra of the original montmorillonite K10 powder; pure ionic liquids BMImNTf $_{2}$, BMImOTf, and BMImDCA; and MMT K10 samples modified with ionic liquids are compared in Figures 8-10 in the region of $4000-400 \mathrm{~cm}^{-1}$. The bands of MMT K10 at 3622 and $3670 \mathrm{~cm}^{-1}$ (a shoulder; trace (a) in Figures 8-10) correspond to the interlayer hydroxyl stretching $(v \mathrm{Si}-\mathrm{OH})[40,41]$. The broad band at ca. $3427 \mathrm{~cm}^{-1}$ and the minor peak at $1633 \mathrm{~cm}^{-1}$ have been assigned to the stretching $(v \mathrm{OH})$ and bending $(\delta \mathrm{OH})$ modes of absorbed water. The silicon-oxygen $(v \mathrm{SiO})$ and aluminum-oxygen $(v \mathrm{AlO})$ bonds are observed at $1049 \mathrm{~cm}^{-1}$ and $620 \mathrm{~cm}^{-1}$ (a shoulder), and the magnesium-oxygen $(v \mathrm{MgO})$ bond is assigned to the band between 470 and $530 \mathrm{~cm}^{-1}$ [41,42]. The assignments of the important bands of the pure MMT K10 clay and pure ionic liquids are listed in Table 4, according to [40-45].

The FTIR spectra of all the modified MMT K10 are quite similar to those of the ionic liquids. In the MMT K10/BMImNTf 2 spectrum, the $v \mathrm{OH}$ band at $3427 \mathrm{~cm}^{-1}$ from MMT K10 is observed in the form of a small wave centered at $3600 \mathrm{~cm}^{-1}$ (trace (c) in Figure 8), which indicates that the addition of BMImNTf 2 leads to a decrease in bound water. The peaks at $2800-3200 \mathrm{~cm}^{-1}$ from the BMImNTf $\mathrm{Binic}_{2}$ liquid are practically unaffected, since their displacements do not exceed the instrumental resolution $\left(2 \mathrm{~cm}^{-1}\right)$. The spectrum from 1300 to $800 \mathrm{~cm}^{-1}$ is a superposition of bands from the ionic liquid and clay, due to oxygen-containing groups (Table 4), and therefore cannot provide much information. However, in the range of 600-400 $\mathrm{cm}^{-1}$, there is one peak from MMT K10, which changes in comparison with pure clay. The same trend is observed in the spectrum of MMT K10/BMImOTf, but the $v \mathrm{OH}$ peak appears at a lower frequency, about $3540 \mathrm{~cm}^{-1}$ (trace (c) in Figure 9), which indicates that water is associated with an ionic liquid (mainly with the [OTf] ${ }^{-}$anion) [46]. 


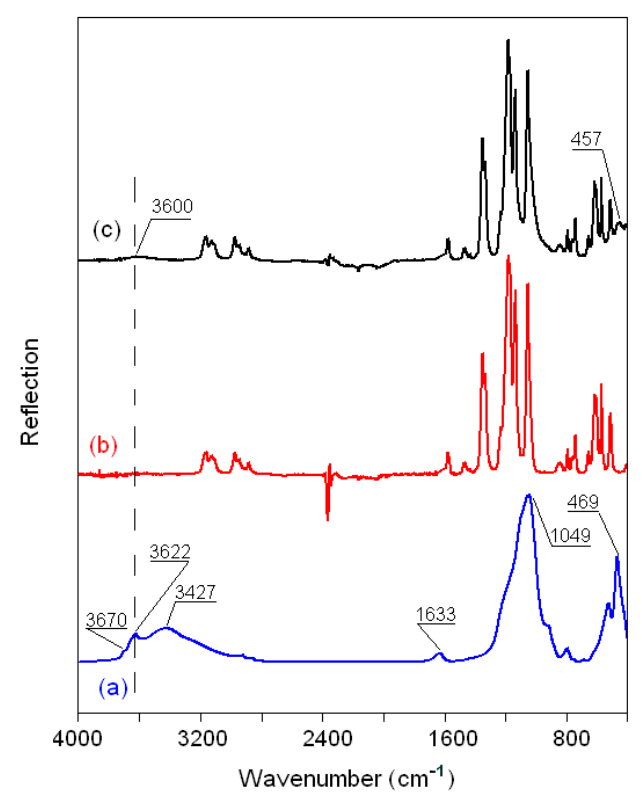

Figure 8. FTIR spectra of (a) MMT K10, (b) BMImNTf 2 , and (c) MMT K10/BMImNTf 2 .

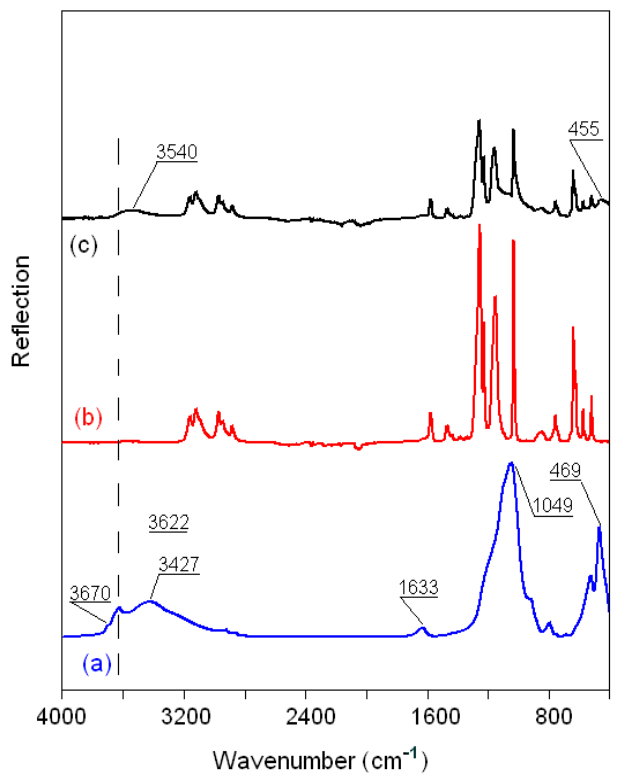

Figure 9. FTIR spectra of (a) MMT K10, (b) BMImOTf, and (c) MMT K10/BMImOTf.

In the MMT K10/BMImDCA spectrum, the wave from $v \mathrm{OH}$ modes is already at $3440 \mathrm{~cm}^{-1}$, and the $v \mathrm{SiO}$ mode of pure MMT K10 $\left(1049 \mathrm{~cm}^{-1}\right)$ is clearly observed and shifted from 1049 in pure clay to $1023 \mathrm{~cm}^{-}$(trace (c) in Figure 10). In addition, more information can be observed in the frequency range of the cation (2300-2050 $\left.\mathrm{cm}^{-1}\right)$ and anion $\left(1600-1300 \mathrm{~cm}^{-1}\right)$. For example, for the [BMIm] $]^{+}$cation, new bands are observed at 1507 and $1410 \mathrm{~cm}^{-1}$, and the peaks at $1302 \mathrm{~cm}^{-1}\left(\delta_{\mathrm{as}}\right.$ ip ring and $\delta C C C C$ modes) and $2123-2225 \mathrm{~cm}^{-1}\left(v_{\mathrm{s}}(\mathrm{N} \equiv \mathrm{C})\right.$ mode) show blue shifts of about $2-4 \mathrm{~cm}^{-1}$. It has also been found that the $v(\mathrm{Mg}-\mathrm{O})$ mode of pure MMT K10 shows a red shift $(\Delta)$ to the lower frequency range in the spectra of all the modified MMT K10, the $\Delta v(\mathrm{Mg}-\mathrm{O})$ values are 12,14 , and $12 \mathrm{~cm}^{-1}$ for the MMT K10/BMImNTf 2 , MMT K10/BMImOTf, and MMT K10/BMImDCA samples, respectively. 


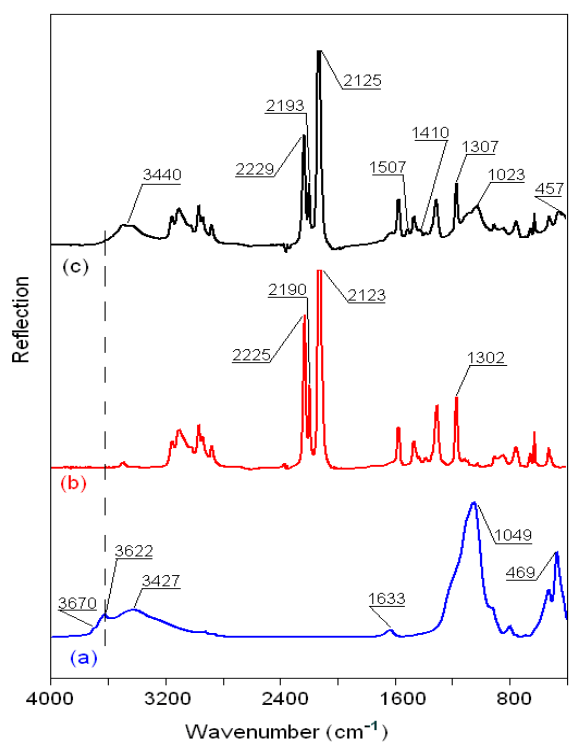

Figure 10. FTIR spectra of (a) MMT K10, (b) BMImDCA, and (c) MMT K10/MImDCA.

Table 4. Some important peaks in the FTIR spectra of pure ionic liquids BMImNTf 2 , BMImOTf, and BMImDCA, as well as pure MMT K10 clay, and their assignments.

\begin{tabular}{|c|c|}
\hline Wavenumber $\left(\mathrm{cm}^{-1}\right)$ & Assignment [40-45] \\
\hline \multicolumn{2}{|l|}{ Clay } \\
\hline $3630-3700$ & $v \mathrm{Si}-\mathrm{OH}$ \\
\hline $3300-3500$ & $v \mathrm{OH}\left(\mathrm{H}_{2} \mathrm{O}\right)$ \\
\hline 1633 & $\delta \mathrm{OH}\left(\mathrm{H}_{2} \mathrm{O}\right)$ \\
\hline 1049 & $\nu \mathrm{SiO}(\mathrm{Si}-\mathrm{O}-\mathrm{Si})$ \\
\hline 620 & $v \mathrm{AlO}(\mathrm{Al}-\mathrm{O}-\mathrm{Al})$ \\
\hline $529-469$ & $v \mathrm{MgO}(\mathrm{Mg}-\mathrm{O}-\mathrm{Mg})$ \\
\hline \multicolumn{2}{|l|}{ Ionic liquid } \\
\hline $3000-32000$ & $v_{\mathrm{as}} \mathrm{H}(\mathrm{C} 4,5) \mathrm{H}, v_{\mathrm{s}} \mathrm{H}(\mathrm{C} 4,5) \mathrm{H}, v \mathrm{C} 2 \mathrm{H}$ \\
\hline $2800-3000$ & $v \mathrm{CH}_{3}, v \mathrm{CH}_{2}, v \mathrm{NH}$ \\
\hline $2100-2300$ & $v_{\mathrm{s}}(\mathrm{N} \equiv \mathrm{C})$ \\
\hline $1150-1600^{\text {a }}$ & $v \mathrm{CH}_{2}(\mathrm{~N}), v \mathrm{CH}_{3}(\mathrm{~N})$, ring $\mathrm{CH}_{3}$ and $v \mathrm{CN}, v C C C \mathrm{C}, \delta_{\mathrm{as}}$ ip ring and $\delta \mathrm{CCCC}, \delta \mathrm{CH}_{3}(\mathrm{~N}) \mathrm{CN}$ \\
\hline $1000-1200^{\mathrm{b}}$ & $v_{\mathrm{s}} \mathrm{SO}_{3}, v_{\mathrm{s}} \mathrm{CF}_{3}$ \\
\hline $1100-1200^{\mathrm{b}}$ & $v_{\mathrm{as}} \mathrm{CF}_{3}$ \\
\hline $1000-1050^{\mathrm{b}}$ & $v_{\mathrm{S}} \mathrm{SO}_{3}$ \\
\hline $1300-137^{\circ} \mathrm{C}$ & $v_{\mathrm{as}} \mathrm{SO}_{2}$ \\
\hline $1110-125^{\circ} \mathrm{C}$ & $v_{\mathrm{s}} \mathrm{CF}_{3}, v_{\mathrm{as}} \mathrm{CF}_{3}, v_{\mathrm{s}} \mathrm{SO}_{2}$ \\
\hline $1000-180^{\circ} \mathrm{C}$ & $v_{\mathrm{a}} \mathrm{SNS}$ \\
\hline
\end{tabular}

a. Peaks observed in the BMImDCA spectrum; b. peaks observed in the BMImOTf spectrum; ${ }^{\mathrm{c}}$ peaks observed in theBMImNTf $f_{2}$ spectrum; $v_{\mathrm{s}}$ and $v_{\text {as }}$ : symmetric and asymmetric stretching, respectively; $\delta_{\mathrm{s}}$ and $\delta_{\mathrm{as}}$ : symmetric and asymmetric bending, respectively.

Thus, the characteristic frequencies of the initial components have noticeable multidirectional shifts, caused by the replacement of water molecules adsorbed by the clay with molecules of the added salt, followed by the interaction of ionic liquid with both clay and water. The interaction of water and clay with confined ionic liquid changes in the series $\left[\mathrm{NTf}_{2}\right]^{-}<[\mathrm{Otf}]^{-}<[\mathrm{DCA}]^{-}$, in accordance with the decrease in hydrophilicity of the anion in the series $[\mathrm{DCA}]^{-}>[\mathrm{Otf}]^{-}>\left[\mathrm{NTf}_{2}\right]^{-}$, and in accordance with an increase in the size of the anion in the series $[\mathrm{DCA}]^{-}<[\mathrm{OTf}]^{-}<\left[\mathrm{NTf}_{2}\right]^{-}$. The interaction of montmorillonite K10 with ionic liquids occurs mainly due to electrostatic bonds of the cation with the silane group $\mathrm{SiO}$ (as well as with $\mathrm{MgO}$ ) of clay. It can be assumed that the dicyanamide anion, due to its small size, also interacts with the silanol group through the hydrogen bond $\mathrm{Si}-\mathrm{OH} \cdots \mathrm{N}$.

In summary, we can say the following. The melting point and thermal stability determine the range of the liquid state of an IL, and therefore, the area of their application. For clay-thickened 
ionic liquids, it is important that the temperature range in which the IL exhibits the properties of a low-temperature melt expands compared to pure $\mathrm{IL}$, and that the decrease in melting point and thermal stability are insignificant. This allows the use of IL as part of solid-state devices without loss of quality.

Both the melting point and thermal stability of ILs are largely dependent on intramolecular and intermolecular interactions. Coulomb forces between the anion and the cation, van der Waals bonds between alkyl chains of imidazolium rings, and $\mathrm{H}$-bonds are the most important interactions in ionic liquids. Therefore, the melting point and thermal stability of ILs depend on the type of both the cation and the anion. At the same time, for IL-clay composites, these parameters will also depend on the interaction of IL with the clay surface. To determine the effect of anion types of ILs on the thermal behaviour of nanocomposites, the interaction of an IL based on 1-butyl-3-methylimidazole with montmorillonite $\mathrm{K} 10$ was first studied.

Montmorillonite K10 is acid-treated clay with a highly developed porous structure, which has a significant adsorption capacity and high catalytic activity in various reactions of organic synthesis. It was found that the interaction of the IL with MMT K10 occurs due to the processes of desorption of water molecules from the clay surface and the adsorption of the IL's molecules; in addition, the confined ionic liquid interacts with both clay and water. Hydrophobic IL partially replaces water, while hydrophilic IL is introduced into a layer of water adsorbed on the surface of the clay. These processes depend on the nature of the anion, and lead to noticeable multidirectional shifts of the characteristic frequencies in the IR spectra of the original components. It was found that the interaction of confined ionic liquid with MMT K10 and adsorbed water changes in the following order: [DCA $]^{-}$ $>[\mathrm{OTf}]^{-}>\left[\mathrm{NTf}_{2}\right]^{-}$, in accordance with the increase in hydrophilicity and decrease in the size of the anion. MMT K10 interacts with ionic liquids mainly due to electrostatic and van der Waals bonds of the cation with the silane groups of clay. The anion dicyanamide apparently also interacts with silanol groups through hydrogen bonds.

Based on these data, it can be assumed that the decrease in thermal stability of confined ILs is related to their interaction with the surface of MMT K10, as well as changes in the hydrate state of the clay resulting from interaction with the ionic liquid. This is clearly demonstrated by the TG data. Heating nanocomposites based on hydrophobic ILs MMT K10/BMImOTf and MMT K10/BMImNTf 2 does not lead to mass change, due to the removal of adsorbed water. On the contrary, heating the MMT K10/BMImDCA composite with a hydrophilic ionic liquid is accompanied by a significant decrease in mass due to the removal of $\mathrm{H}_{2} \mathrm{O}$. At the same time, the thermal stability of ILs decreases by about $30{ }^{\circ} \mathrm{C}$. Thus, the highly developed surface of the acid-treated MMT K10 contributes to the thermal decomposition of the adsorbed IL.

\section{Conclusions}

In this work, composites based on montmorillonite K10 and ionic liquid 1-butyl-3-methylimidazole with various anions, such as bis (trifluoromethylsulfonyl) imide, trifluoromethanesulfonate, and dicyanamide were studied for the first time. The thermal behaviour of the MMT K10/IL composite and the corresponding IL have been compared by the DSC and TG methods. It has been identified that the anion nature in the IL affects phase transitions in the materials in question. It has also been found that pure ILs have higher (by $30-40{ }^{\circ} \mathrm{C}$ ) characteristic temperatures of thermal decomposition compared to the corresponding MMT K10/IL composites. Based on the data obtained by the XRD and FTIR methods, it has been concluded that the presence of an IL leads to water removal from the interlayer space in the clay. The interaction of IL and MMT K10 depends on the nature of the ionic liquid anion. Molecules of the ionic liquids are immobilized mainly on the surface of the clay, and interact with molecules of adsorbed water.

Author Contributions: Conceptualization, E.G. and V.I.; formal analysis, A.A.; investigation, O.A., A.N., and L.R.; methodology, N.K.

Funding: This research was funded by the Russian Foundation for Basic Research (grant No. 18-29-12012). 
Acknowledgments: TG and DSC measurements were performed on the equipment of the Upper Volga Regional Center for Physicochemical Studies Center for Collective Use.

Conflicts of Interest: The authors declare no conflict of interest.

\section{References}

1. Galamboš, M.; Suchánek, P.; Rosskopfová, O. Sorption of anthropogenic radionuclides on natural and synthetic inorganic sorbents. J. Radioanal. Nucl. Chem. 2012, 293, 613-633. [CrossRef]

2. Takahashi, C.; Shirai, T.; Fuji, M. Study on intercalation of ionic liquid into montmorillonite and its property evaluation. Mater. Chem. Phys. 2012, 135, 681-686. [CrossRef]

3. Bee, S.-L.; Abdullah, M.A.A.; Bee, S.-T.; Sin, L.T.; Rahmat, A.R. Polymer nanocomposites based on silylated-montmorillonite: A review. Prog. Polym. Sci. 2018, 85, 57-82. [CrossRef]

4. Alekseeva, O.V.; Rodionova, A.N.; Bagrovskaya, N.A.; Agafonov, A.V. Synthesis, structure, and properties of a bentonite-magnetite composite. Prot. Met. Phys. Chem. Surf. 2016, 52, 819-824. [CrossRef]

5. Chen, C.; Ma, Y.; Wang, C. Investigation of electrochemical performance of montmorillonite clay as Li-ion battery electrode. Sustain. Mater. Technol. 2019, 19, e00086. [CrossRef]

6. Butman, M.F.; Ovchinnikov, N.L.; Karasev, N.S.; Kochkina, N.E.; Agafonov, A.V.; Vinogradov, A.V. Photocatalytic and adsorption properties of $\mathrm{TiO}_{2}$-pillared montmorillonite obtained by hydrothermally activated intercalation of titanium polyhydroxocomplexes. Beilstein J. Nanotechnol. 2018, 9, 364-378. [CrossRef]

7. Bouazizi, N.; Barrimo, D.; Nousir, S.; Ben Slama, R.; Shiao, T.C.; Roy, R.; Azzouz, A. Metal-loaded polyol-montmorillonite with improved affinity towards hydrogen. J. Energy Inst. 2018, 91, 110-119. [CrossRef]

8. Bouazizi, N.; Barrimo, D.; Nousir, S.; Ben Slama, R.; Roy, R.; Azzouz, A. Montmorillonite-supported Pd ${ }^{0}$, $\mathrm{Fe}^{0}, \mathrm{Cu}^{0}$ and $\mathrm{Ag}^{0}$ nanoparticles: Properties and affinity towards $\mathrm{CO}_{2}$. Appl. Surf. Sci. 2017, 402, 314-322. [CrossRef]

9. Fontana, J.P.; Camilo, F.F.; Bizeto, M.A.; Faez, R. Evaluation of the role of an ionic liquid as organophilization agent into montmorillonite for NBR rubber nanocomposite production. Appl. Clay Sci. 2013, 83-84, $203-209$. [CrossRef]

10. Dedzo, G.K.; Detellier, C. Clay minerals—ionic liquids, nanoarchitectures, and applications. Adv. Funct. Mater. 2017, 28, 1703845. [CrossRef]

11. Montano, D.F.; Casanova, H.; Cardona, W.I.; Giraldo, L.F. Functionalization of montmorillonite with ionic liquids based on 1-alkyl-3-methylimidazolium: Effect of anion and length chain. Mater. Chem. Phys. 2017, 198, 386-392. [CrossRef]

12. Zhao, X.; Cai, P.; Sun, C.; Yuanjiang Pan, Y. Application of ionic liquids in separation and analysis of carbohydrates: State of the art and future trends. TrAC-Trend. Anal. Chem. 2019, 111, 148-162. [CrossRef]

13. Hallett, J.P.; Welton, T. Room-temperature ionic liquids. Solvents for synthesis and catalysis 2. Chem. Rev. 2011, 111, 3508-3576. [CrossRef]

14. Wishart, J.F. Energy applications of ionic liquids. Energy Environ. Sci. 2009, 2, 956-961. [CrossRef]

15. Welton, T. Ionic liquids: A brief history. Biophys. Rev. 2018, 10, 691-706. [CrossRef]

16. Fedorov, M.V.; Kornyshev, A.A. Towards understanding the structure and capacitance of electrical double layer in ionic liquids. Electrochim. Acta 2008, 53, 6835-6840. [CrossRef]

17. Fedorov, M.V.; Kornyshev, A.A. Ionic liquid near a charged wall: Structure and capacitance of electrical double layer. J. Phys. Chem. B 2008, 112, 11868-11872. [CrossRef]

18. Dedzo, G.K.; Detellier, C. Characterization and applications of kaolinite robustly grafted by an ionic liquid with naphthyl functionality. Materials 2017, 10, 1006. [CrossRef]

19. Selvam, T.; MacHoke, A.; Schwieger, W. Supported ionic liquids on non-porous and porous inorganic materials-A topical review. Appl. Catal. A-Gen. 2012, 445-446, 92-101. [CrossRef]

20. Fiscal-Ladino, J.A.; Obando-Ceballos, M.; Rosero-Moreano, M.; Montano, D.F.; Cardona, W.; Giraldo, L.F.; Ritcher, P. Ionic liquids intercalated in montmorillonite as the sorptive phase for the extraction of low-polarity organic compounds from water by rotating-disk sorptive extraction. Anal. Chim. Acta 2017, 953, $23-31$. [CrossRef] 
21. Takahashi, C.; Shirai, T.; Hayashi, Y.; Fuji, M. Study of intercalation compounds using ionic liquids into montmorillonite and their thermal stability. Solid State Ion. 2013, 241, 53-61. [CrossRef]

22. Jha, A.; Garade, A.C.; Shirai, M.; Rode, C.V. Metal cation-exchanged montmorillonite clay as catalysts for hydroxyalkylation reaction. Appl. Clay Sci. 2013, 74, 141-146. [CrossRef]

23. Huddleston, J.G.; Visser, A.E.; Reichert, W.M.; Willauer, H.D.; Broker, G.A.; Rogers, R.D. Characterization and comparison of hydrophilic and hydrophobic room temperature ionic liquids incorporating the imidazolium cation. Green Chem. 2001, 3, 156-164. [CrossRef]

24. Fredlake, C.P.; Crosthwaite, J.M.; Hert, D.G.; Aki, N.V.K.; Brennecke, J.F. Termophysical properties of imidazolium-based ionic liquids. J. Chem. Eng. Data 2004, 49, 954-964. [CrossRef]

25. Marcus, Y. Ionic and molar volumes of room temperature ionic liquids. J. Mol. Liq. 2015, 209, $289-293$. [CrossRef]

26. Hunt, P.A.; Ashworth, C.R.; Matthews, R.P. Hydrogen bonding in ionic liquids. Chem. Soc. Rev. 2015, 44, 1257-1288. [CrossRef]

27. Deng, M.J.; Chen, P.Y.; Leong, T.-I.; Sun, I.-W.; Chang, J.K.; Tsai, W.T. Dicyanamide anion based ionic liquids for electrodeposition of metals. Electrochem. Commun. 2008, 10, 213-216. [CrossRef]

28. Macfarlane, D.R.; Tachikawa, N.; Forsyth, M.; Pringle, J.M.; Howlett, P.C. Energy applications of ionic liquids. Energ. Environ. Sci. 2014, 7, 232-250. [CrossRef]

29. Wang, Y.-C.; Lee, T.-C.; Lin, J.-Y.; Chang, J.-K.; Tseng, C.-M. Corrosion properties of metals in dicyanamide-based ionic liquids. Corros. Sci. 2014, 78, 81-88. [CrossRef]

30. Maiti, S.; Pramanik, A.; Chattopadhyay, S.; De, G.; Mahanty, S. Electrochemical energy storage in montmorillonite K10 clay based composite as supercapacitor using ionic liquid electrolyte. J. Colloid Interf. Sci. 2016, 464, 73-82. [CrossRef]

31. He, H.; Guo, J.; Xie, X.; Lin, H.; Li, L. A microstructural study of acid-activated montmorillonite from Choushan, China. Clay Miner. 2002, 37, 337-344. [CrossRef]

32. ALOthman, Z.A. A review: Fundamental aspects of silicate mesoporous materials. Materials 2012, 5, 2874-2902. [CrossRef]

33. Gerasin, V.A.; Antipov, E.M.; Karbushev, V.V.; Kulichikhin, V.G.; Karpacheva, G.P.; Talroze, R.V.; Kudryavtsev, Y.V. New approaches to the development of hybrid nanocomposites: From structural materials to high-tech applications. Russ. Chem. Rev. 2013, 82, 303-332. [CrossRef]

34. Tokuda, H.; Ishii, K.; Susan, M.A.B.H.; Tsuzuki, S.; Hayamizu, K.; Watanabe, M. Physicochemical Properties and Structures of Room-Temperature Ionic Liquids. 3. Variation of Cationic Structures. J. Phys. Chem. B 2006, 110, 2833-2839. [CrossRef]

35. Varadwaj, G.B.B.; Rana, S.; Parida, K.M. Amine functionalized K10 montmorillonite: A solid acid-base catalyst for the Knoevenagel condensation reaction. Dalton Trans. 2013, 42, 5122-5129. [CrossRef]

36. Tabernero, V.; Camejo, C.; Terreros, P.; Alba, M.D.; Cuenca, T. Silicoaluminates as "support activator" systems in olefin polymerization processes. Materials 2010, 3, 1015-1030. [CrossRef]

37. Ramenskaya, L.M.; Grishina, E.P.; Kudryakova, N.O. Physicochemical features of short-chain 1-alkyl-3-methylimidazolium bis(trifluoromethylsulfonyl)-imide ionic liquids containing equilibrium water absorbed from air. J. Mol. Liq. 2018, 272, 759-765. [CrossRef]

38. Ngo, H.L.; LeCompte, K.; Hargens, L.; McEwen, A.B. Thermal properties of imidazolium ionic liquids. Thermochim. Acta 2000, 357-358, 97-102. [CrossRef]

39. Grishina, E.P.; Ramenskaya, L.M.; Gruzdev, M.S.; Kraeva, O.V. Water effect on physicochemical properties of 1-butyl-3-methylimidazolium based ionic liquids with inorganic anions. J. Mol. Liq. 2013, 177, 267-272. [CrossRef]

40. Tonle, I.K.; Letaief, V.; Ngamenic, E.; Detellier, C. Nanohybrid materials from the grafting of imidazolium cations on the interlayer surfaces of kaolinite. Application as electrode modifier. J. Mater. Chem. 2009, 19, 5996-6003. [CrossRef]

41. Ahmed, A.; Chaker, Y.; Belarbi, E.H.; Abbas, O.; Chotard, J.N.; Abassi, H.B.; Van Nhien, A.N.; Hadri, M.E.; Bresson, S. XRD and ATR/FTIR investigations of various montmorillonite clays modified by monocationic and dicationic imidazolium ionic liquids. J. Mol. Struct. 2018, 1173, 653-664. [CrossRef]

42. Kim, N.H.; Malhotra, S.V.; Xanthos, M. Modification of cationic nanoclays with ionic liquids. Micropor. Mesopor. Mat. 2006, 96, 29-35. [CrossRef] 
43. Vitucci, F.M.; Trequattrini, F.; Palumbo, O.; Brubach, J.-B.; Roy, P.; Paolone, A. Infrared spectra of bis(trifluoromethanesulfonyl)imide based ionic liquids: Experiments and DFT simulations. Vib. Spectrosc. 2014, 74, 81-87. [CrossRef]

44. Heimer, N.E.; Del Sesto, R.E.; Meng, R.E.; Wilkes, J.S.; Carper, W.R. Vibrational spectra of imidazolium tetrafluoroborate ionic liquids. J. Mol. Liq. 2006, 124, 84-95. [CrossRef]

45. Ferry, A.; Edman, L.; Forsyth, M.; MacFarlane, D.R.; Sun, J. NMR and Raman studies of a novel fast-ion-conducting polymer-in-salt electrolyte based on $\mathrm{LiCF}_{3} \mathrm{SO}_{3}$ and PAN. Electrochim. Acta 2000, 45, 1237-1242. [CrossRef]

46. Cammarata, L.; Kazarin, S.G.; Salter, P.A.; Welton, T. Molecular states of water in room temperature ionic liquids. Phys. Chem. Chem. Phys. 2001, 3, 5192-5200. [CrossRef]

(C) 2019 by the authors. Licensee MDPI, Basel, Switzerland. This article is an open access article distributed under the terms and conditions of the Creative Commons Attribution (CC BY) license (http://creativecommons.org/licenses/by/4.0/). 